\section{PSICOLOGÍA IBEROAMERICANA}

\section{Psicología lberoamericana}

ISSN: 1405-0943

psicología.iberoamericana@uia.mx

Universidad Iberoamericana, Ciudad de

México

México

Cruz del Castillo, Cinthia

Sociedades actuales, ¿determinadas por las emociones?

Psicología Iberoamericana, vol. 21, núm. 2, julio-diciembre, 2013, pp. 5-6

Universidad Iberoamericana, Ciudad de México

Distrito Federal, México

Disponible en: http://www.redalyc.org/articulo.oa?id=133930525001

- Cómo citar el artículo

- Número completo

- Más información del artículo

Página de la revista en redalyc.org

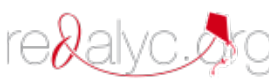

Sistema de Información Científica

Red de Revistas Científicas de América Latina, el Caribe, España y Portugal

Proyecto académico sin fines de lucro, desarrollado bajo la iniciativa de acceso abierto 


\section{EDITORIAL \\ Sociedades actuales, ¿determinadas por las emociones?}

Sin pretenderlo, este número conjunta, casi en su totalidad, trabajos sobre la ansiedad y la depresión, hecho que desata algunas preguntas: ¿la ansiedad y la depresión son características que van de la mano con la "vida moderna"?, ¿son etiquetas cada vez más fáciles de asignar en uno mismo y en los otros sin un diagnóstico especializado?, ¿o más bien somos sociedades sin habilidades para regular las emociones carentes de estrategias para la solución de lo cotidiano?

Desde hace varias décadas, los teóricos ya señalaban las influencias sociales en la expresión de las emociones conocidas como "reglas emocionales", que son el control social sobre la expresión y la pertinencia de las emociones de acuerdo con cada situación y contexto. Dentro de cada cultura se aprenden las normas, las creencias y el vocabulario prevalente para cada emoción. De este modo, la mayoría de las experiencias emocionales surge en un contexto social y, especialmente, en el de las relaciones íntimas (Clark \& Reis, 1988; Shott, 1979). Así, por ejemplo, el miedo es una consecuencia de la amenaza a un rechazo o la pérdida de una relación; la tristeza es causada por la enfermedad o la muerte de la pareja; el enojo se produce por la pérdida del respeto o por un insulto; la alegría es causada por recibir reconocimiento o por ser objeto de afecto, mientras que el amor es exclusivamente interpersonal.

Estar alerta de las emociones permitirá, por tanto, evaluar si éstas son situacionalmente pertinentes o si de alguna manera hay una sobrevaloración, ya sea por el contexto en el que las aprendimos o por la relación interpersonal a la que las estamos ligando.

Las colaboraciones de este número ofrecen respuestas ante los altos porcentajes de personas que se perciben con ansiedad y depresión en la actualidad. El primer texto, de Reyes, describe un modelo de intervención orientado a la resolución de dificultades de regulación emocional, que integra elementos de terapias metacognitiva y conductual-contextuales. El segundo trabajo, de Sarudiansky, realiza un recorrido etimológico y conceptual sobre la ansiedad, intentando reflejar la variabilidad de contenidos que presenta en la actualidad este término. El tercer trabajo, de Nogueda, Pérez, Barriento, Robles y Sierra, valida un instrumento llamado Hospital Anxiety and Depression Scale (HADS), en su versión en español para pacientes mexicanos con diagnóstico de virus de inmunodeficiencia humana. En cuarto sitio aparece el trabajo de Córdova, Rosales y Reyes que registra la presencia de ideación suicida en estudiantes universitarios guerrerenses. La quinta aportación a este número es de Orantes, Ayala-Guerrero, Méndez, Oropeza y Juárez, quienes estudiaron los

\footnotetext{
* Correspondencia: Prolongación Paseo de la Reforma 880, Edificio J Segundo Piso, Lomas de Santa Fe, C. P. 01219, México, D. F. Tel. (52) (55) 59504000 ext. 7013 cinthia.cruz@ibero.mx
} 
efectos sobre el sueño en dependientes a la cocaína en abstinencia. La sexta contribución la hacen Martínez-Jerez y Morales-Carmona, quienes adaptan la encuesta de proyectos de vida en estudiantes universitarios de Tamaulipas. En séptimo sitio figura la validación de la Escala de Ansiedad Social en una muestra de adolescentes realizada por Jiménez, Sánchez y Valencia. Finalmente, la investigación de Espinosa, Mayoral y Laca presenta datos acerca de si el grado de altruismo en estudiantes se vincula con sus niveles de bienestar social. •

\section{REFERENCIAS}

Clark, M. \& Reis, H.T. (1988). Interpersonal processes in close relationships, 39, 609-672.

Shott, S. (1979). Emotion and social life: A symbolic interactionist analysis. American Journal of Sociology, 84, 1317-1334. 